\title{
Overweight and Obesity Associated with Dietary Habits, Physical Activity and Family Environment in 7-8 Years Old School Children in Pavia, Northern Italy
}

\author{
Giovanna Turconi ${ }^{1}$, Laura Maccarini ${ }^{2 *}$, Eleonora Porzio ${ }^{2}$, Stefania Moro ${ }^{2}$ and Carla Roggi ${ }^{1}$ \\ ${ }^{1}$ Department of Public Health, Experimental and Forensic Medicine, Unit of Human Nutrition and Dietetics, Italy \\ ${ }^{2}$ Department of Public Health, Experimental and Forensic Medicine, Unit of Hygiene and Preventive Medicine. \\ Faculty of Medicine, University of Pavia, 27100, Pavia, Italy
}

\begin{abstract}
Received: December 16, 2015; Accepted: January 29, 2016; Published: February 04, 2016
*Corresponding author: Laura Maccarini, Department of Public Health, Experimental and Forensic Medicine-Unit of Hygiene and Preventive Medicine, Faculty of Medicine, University of Pavia , Italy Via Forlanini, 2 I - 27100 Pavia, Italy, Tel: + 00390382 987280; E-mail: laura.maccarini@unipv.it
\end{abstract}

\begin{abstract}
Childhood obesity has reached epidemic proportions during the last three decades. Its prevalence rate is rising almost universally with an increased risk for developing chronic diseases such as type 2 diabetes, cardiovascular disease and a variety of other co-morbidities before or during early adulthood. The association of dietary behaviors, physical activity and sedentary lifestyle with childhood obesity has been explored among school-aged children in various countries. Family background factors such as parental overweight and low educational level and socio-economic status have been reported to be associated with an increased prevalence of overweight/obesity among children.
\end{abstract}

The aim of this cross-sectional study was to investigate the correlation between overweight/obesity and dietary habits, physical activity and family environment among children attending the second year of primary schools in Pavia, Northern Italy, in 2012. Pupils' weight and height were measured in standard conditions by two trained dietitians. Dietary habits, physical activity, family environment and parents' BMI were investigated by means of a structured questionnaire filled in by the parents themselves.

Multiple logistic regression analysis was used to assess the effects of family environment and children's physical activity on children's obesity.

The results showed a correlation between all the covariates and children's obesity, except for children's dietary habits, OR ranging from 1.163 (95\% CI 1.067-1.269) for fathers' BMI to 2.101 (95\% CI 1.124-3.926) for children's physical activity and $p<0.05$ for all the significantly correlated variables.

In conclusion family environment seemed to influence the prevalence of overweight and obesity in our sample. These findings strengthen the need for implementing public health interventions and educational strategies in primary schools aimed at involving the parents to achieve children's consistent behavioral changes.

Keywords: Children, Obesity, Family Environment, Cross Sectional Study, Northern Italy

\section{Introduction}

Obesity has reached epidemic proportions and children's obesity has been described as the main health-related problem worldwide, due to its link with physical, social and psychological consequences [1]. Global prevalence of childhood obesity has increased greatly during the last three decades [2]. Its prevalence rate is rising almost universally [3-6] with an increased risk for developing chronic diseases such as type 2 diabetes, cardiovascular disease and a variety of other co-morbidities before or during early adulthood.

The prevalence of overweight and obese children is dramatically higher in economically developed regions, but is rising significantly in most areas of the world [4,6]. Recent data from the International Association for the Study of Obesity (IASO) [6] showed that prevalence of overweight/obesity, in the WHO Regions, respectively in boys and girls, was $1.9 \%$ and 2.6\% in African Regions, $27.3 \%$ and 26.3\% in American Regions, $15.2 \%$ and $16.6 \%$ in the Eastern Mediterranean Regions, $22.1 \%$ and $20.3 \%$ in European Regions, $14.2 \%$ and $7.0 \%$ in South East Asian Regions, $17.7 \%$ and $12.7 \%$ in Western Pacific Regions.

A cross-sectional survey carried out in 2014 by the Italian Ministry of Health and coordinated by the National Institute of Health on 48,426 students aged 8-9 years (OKkio alla Salute Surveillance Project, 2014) [7] showed that among all of the pupils weighed and measured using the international standardized methodology, $30.7 \%$ were overweight or obese, with the highest percentage in Central $(>30 \%)$ and Southern Italy $(>37 \%)$. The Italian data remain higher than those from other European Countries (Belgium, Ireland, Norway, Portugal Hungary), although showing a decrease of 4.5\% since 2008-09 to 2014. Furthermore, our national data subdivided according to geographical areas showed in Lombardy Region a prevalence rate of overweight/obesity decreasing from $25-33 \%$ in 2008 to s $25 \%$ in 2014 [7]. 
Unhealthy eating patterns, such as a high consumption of sugar-sweetened soft drinks, snacks and sweets, and a low number of daily meals of fruit and vegetable portions as well as the habit of skipping breakfast, were related to overweight in children [8-10]. Moreover, the association of dietary behaviors, physical activity and sedentary lifestyle with childhood obesity was explored among school-aged children in various countries [11-13].

In addition, family background factors such as parental overweight and low educational level and socio-economic status, as well as lifestyle factors such a slow physical activity level or sedentary behavior were reported to be associated with an increased prevalence of overweight/obesity among children. It has been shown that in developed countries parental overweight and a low educational and socio-economic status are major potential determinants of increasing risk of overweight and obese children, while this correlation is inverse in developing countries [10,11,14-16].

This study aimed at investigating the correlation between overweight plus obesity and dietary habits, physical activity and family environment among children attending the second year of primary schools in Pavia, Northern Italy, since some similar studies are recently available, but only for Central and Southern Italy.

\section{Methods}

\section{Sample}

In this cross-sectional study, all children of both sexes attending the second year of all the primary schools $(n=13)$ in Pavia, Northern Italy, were recruited $(\mathrm{n}=470)$ in 2012.

We decided to select only the second year primary school pupils, as we intend to follow them up until the last year of primary school after a nutritional education intervention provided by the school teachers.

This study was carried out as part of a wider nutritional surveillance project with the cooperation of the Education Department of Pavia City Hall, which also included an investigation either on the meals consumed in school canteens either on breakfast consumption by the children at their own home. All students were surveyed over the course of three months, from April to the end of June 2012.

Before starting the study, the research team organized several meetings together with teachers to illustrate the aim of the research and to request their participation. Afterward, students and their parents were informed of the study by means of assemblies in each school as well as they were provided with a written document in which the research relevance in the context of an educational surveillance program was outlined. Finally they were invited to participate in the study. Informed written consent was obtained from them by means of a signed letter that the pupils gave back to their teacher. Only 22 remainder calls were needed just once to return consent form.

The study was conducted according to the guidelines laid down in the Declaration of Helsinki and all procedures involving human subjects were approved by the Ethics Committees of Pavia University Medical School.

\section{Data Collection}

Children's anthropometric measurements assessment: All the subjects were examined by two trained dietitians after setting up a classroom as a clinic in each school. The dietitians had received 8 hours of instruction and had been standardized in the measurement assessments. A subset of children (20 males and 20 females) was measured by the two dietitians to determine intra- and inter-operator variability, which was $<3 \%$ for all the measurements (Kappa reliability test).

The assessment was carried out during school hours in the late morning, about an hour before lunch, subject to an appointment with the school teachers.

Measurements of weight and height were taken under standard conditions [17]:

- Body weight, measured to the nearest $0.5 \mathrm{~kg}$ on subjects wearing only underwear and without shoes by means of a steelyard scale (precision $\pm 100 \mathrm{~g}$ );

- $\quad$ Body height measured to the nearest $0.5 \mathrm{~cm}$ on subjects without shoes by means of a stadiometer (precision $\pm 1 \mathrm{~mm}$ );

BMI (Body Mass Index) was computed as the ratio between weight (in kilograms) and the square of height (in meters).

Questionnaire: Dietary habits, physical activity and family environment were investigated by means of a structured questionnaire filled in by the parents. A targeted questionnaire was previously developed and delivered to parents, asking them to complete it. The question aire consisted of four sections:

Section one: included 23 questions relating to family composition, parents' socio-economic status and educational level as well as demographic and anthropometric characteristics (parents' weight and height).

Section two: included 15 questions regarding child's dietary habits. This section was drawn from a previous validated questionnaire, adjusted for children $[18,19]$.

Section three: included 3 questions relating to the hours per week spent in physical activity, the hours per day spent watching $\mathrm{TV}$, using a computer and playing mobile games and the sport regularly practiced during the year.

Section four: included 7 questions concerning family dietary habits and based on the consumption of healthy foods as recommended by WHO dietary guidelines [20].

The items of the questionnaire were developed by a team of three dieticians. The questionnaire was previously piloted on a sample of 52 parents and revised accordingly, but validity and reliability were not formally tested.

Parents reported that took thirty minutes to complete all the questionnaire sections. 


\section{Cut off Values}

In accordance with the International Obesity Task Force (IOTF) Cole et al.'s [21] cut-off point reference standards for BMI [22] were used to identify overweight and obesity at a young age.

\section{Data Analysis}

Data were processed using the Statistical Package for the Social Sciences version 18 for PC (SPSS Inc., Chicago, IL, USA). Descriptive statistics (means and standard deviations) and frequency distribution were calculated for all the variables.

T-test was used for independent samples; Mann-Whitney's test and Pearson's chi-square test were used to assess differences in anthropometric variables between genders.

Pearson's correlation coefficient was used to analyse the correlation between father's and mother's BMI as well as their cultural level.

Crude odds ratio (OR) with 95\% confidence interval (CI 95\%) were calculated to examine the relationship between overweight plus obese children (dependent variable) and dietary habits, physical activity and family environment (independent variables) by multiple logistic regression analysis.

Multiple logistic regression analysis was used to estimate the simultaneous effect of several covariates on a dichotomous outcome. Independent variables were entered into the multivariate model simultaneously to quantify the independent variable effects on overweight plus obesity in terms of adjusted odds ratios.

All associations were considered statistically significant for a $p$-value $<0.05$.

Family income was divided into three social categories: low (up to $€ 30.000$ per year), medium (from $€ 31.000$ to $€ 60.000$ per year) and high (>€ 60.000 per year) as previously used in another study [10].

Answers relating to children's dietary habits [18,19] were evaluated assigning a score ranging from 0 to 3 with the maximum score assigned to the healthiest one and the minimum score to the least one. The total score of this section was 45 . It was divided into three ranges, where the lowest one $(0-20)$ referred to "inadequate eating habits", the medium one (21-35) referred to "partially satisfactory eating habits" and the highest one (3645) referred to "quite satisfactory eating habits".

Each of the seven questions related to family dietary habits and based on the consumption of healthy foods as recommended by WHO dietary guidelines [20] received 1 point if satisfying any recommended food habit, thus totalizing the maximum score of 7. The score was arbitrarily dichotomized as following: 0-3 meaning unhealthy food habits and $\geq 4$ indicating healthy food habits. A similar index was previously used in other studies [23,24].

\section{Results}

\section{Sample}

Out of 470 children recruited for this study, 435 healthy subjects (92.5\% of the entire sample) participated in the study, $52.2 \%$ males and $47.8 \%$ females, among whom 63 were from non-European countries, born in Italy. Thirty five children, 22 Italians and 13 foreigners, refused to participate in the study, since their parents were not interested in the project. None of the eligible children was neither mobility impaired nor disabled nor with medical condition that might affect all data collection.

The mean age of the sample was $7.7 \pm 0.2$ years (range 7-8.5), with a prevalent distribution between 7.5 and 8 years. Six Italian children and ten foreigners were aged above eight years.

All the parents of the children who participated in the survey returned the questionnaire entirely completed.

\section{Children's Anthropometric Measurements}

The anthropometric measurements of the sample are presented in Table 1. Mean BMI value was equal to $16.4 \pm 2.5$ $\mathrm{kg} / \mathrm{m}^{2}$ for boys and $16.2 \pm 2.5 \mathrm{~kg} / \mathrm{m}^{2}$ for girls. According to Cole's cut-off point reference standards [22], $12.4 \%$ and $8.8 \%$ of boys and girls respectively were overweight, while the percentage of obese subjects was $4.9 \%$ in both sexes. Overall, $15.9 \%$ of the all sample was overweight plus obese. Weight and height were slightly higher in boys than in girls, while BMI was similar in both groups. The prevalence rate of underweight subjects was higher in girls; overweight prevalence was higher in boys and normal weight and obese children were similar in the two groups.

\section{Children's Dietary Habits}

Children's eating habits are shown in Table 2 where most significant answers relating to dietary consumption are reported. Most of the children had breakfast (91.8\%) with milk, fruit juice and cereals, consumed five meals per day $(90.8 \%)$, only a few ate dessert (30.0\%) or drank soft drinks (14.8\%) at each meal, nevertheless only about $50 \%$ of them consumed two portions of fruit and vegetables each day.

According to the score used to classify children's dietary habits, only $1.4 \%$ of the children had "inadequate eating habits", $60.8 \%$ showed "partially satisfactory eating habits" and $37.8 \%$ had "quite satisfactory eating habits". Children's eating habits

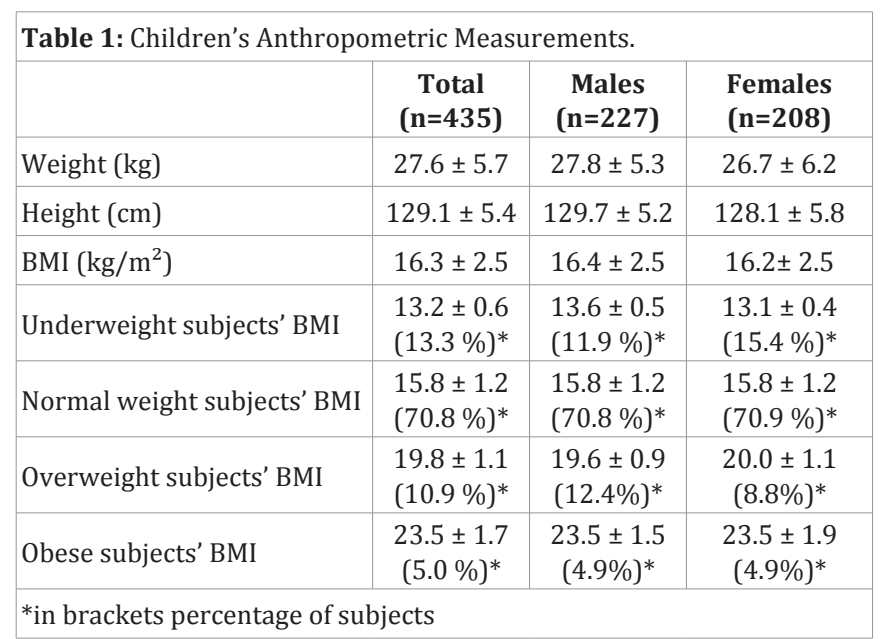


Table 2: Children's Dietary Habits.

\begin{tabular}{|c|c|c|}
\hline & $\mathrm{N}^{\circ}$ & $\%$ \\
\hline \multicolumn{3}{|l|}{ Do you consume breakfast? } \\
\hline Always & 370 & 84.7 \\
\hline Often & 31 & 7.1 \\
\hline \multicolumn{3}{|c|}{ Which beverage do you drink at breakfast? } \\
\hline Milk & 333 & 76.2 \\
\hline Fruit juice & 55 & 12.6 \\
\hline \multicolumn{3}{|c|}{ Children consuming cereal breakfast } \\
\hline & 404 & 92.4 \\
\hline \multicolumn{3}{|c|}{ Do you consume morning snacks? } \\
\hline Always & 286 & 65.4 \\
\hline Often & 104 & 23.9 \\
\hline \multicolumn{3}{|c|}{ Do you consume afternoon snacks? } \\
\hline Always & 323 & 73.9 \\
\hline Often & 89 & 20.4 \\
\hline \multicolumn{3}{|c|}{ Children consuming snacks with } \\
\hline Cereals & 289 & 66.1 \\
\hline Fruit/fruit juice/milk/yogurt & 95 & 21.7 \\
\hline \multicolumn{3}{|c|}{ Do you consume two portions of fruit/day? } \\
\hline Always & 94 & 21.5 \\
\hline Often & 157 & 35.9 \\
\hline \multicolumn{3}{|c|}{ Do you consume two portions of vegetables/day? } \\
\hline Always & 52 & 11.9 \\
\hline Often & 145 & 33.2 \\
\hline \multicolumn{3}{|c|}{ Do you consume dessert at each meal? } \\
\hline Always & 37 & 8.5 \\
\hline Often & 94 & 21.5 \\
\hline \multicolumn{3}{|c|}{ Do you consume soft drink at each meal? } \\
\hline Always & 15 & 3.4 \\
\hline Often & 50 & 11.4 \\
\hline \multicolumn{3}{|c|}{ Do you consume five meals/day? } \\
\hline Always & 250 & 57.2 \\
\hline Often & 147 & 33.6 \\
\hline \multicolumn{3}{|l|}{ Your habitual diet is } \\
\hline Varied & 343 & 78.5 \\
\hline Monotonous & 23 & 5.3 \\
\hline \multicolumn{3}{|c|}{ Which beverages do you consume out of meals? } \\
\hline Water & 239 & 54.7 \\
\hline Fruit juice & 140 & 32.0 \\
\hline Soft drinks & 30 & 6.9 \\
\hline \multicolumn{3}{|c|}{ Do you consume a glass of milk or yogurt/day? } \\
\hline Always & 237 & 54.3 \\
\hline Often & 113 & 25.9 \\
\hline \multicolumn{3}{|c|}{ Do you consume a liter of water/day? } \\
\hline Always & 129 & 29.5 \\
\hline Often & 161 & 36.9 \\
\hline
\end{tabular}

score showed a positive trend with parents' socio-economic and educational levels, nevertheless they did not show a significant correlation $(P=0.097)$.

\section{Children's Physical Activity}

Most of children were physically active given that more than $40 \%$ of them were involved in dynamic outdoor games for one hour or more each day. In addition, $79.8 \%$ of the children were used to practice sport along the year. Sports most practiced were swimming (35.6\%), basket (15.6\%), foot-ball (13.8\%) and dance among girls $(12.2 \%)$. Nevertheless, in winter time, about $80 \%$ of them watched the television, used the computer or played mobile games for one or two hours per day.

\section{Children's Family Characteristics}

Children's family generally included four members, parents and two children, one family reaching twelve subjects including grandparents and some uncles and aunts. In $24.9 \%$ of the families one or more grandparents, in $4.8 \%$ others relatives, were living together.

Mean parents' age was $43.0 \pm 6.1$ and $40.0 \pm 5.7$ years respectively for father and mother. As far as parents' BMI was concerned, mean mothers' BMI was in the normal weight range $\left(22.3 \pm 3.7 \mathrm{~kg} / \mathrm{m}^{2}\right)$ while mean fathers' one was slightly higher than the normal range $\left(25.3 \pm 3.2 \mathrm{~kg} / \mathrm{m}^{2}\right)$. Fifty-two point one percent of fathers and $69.5 \%$ of mothers were normal weight, while $40.1 \%$ of father's and $15.4 \%$ of mother's was overweight and $7.8 \%$ of fathers and $4.2 \%$ of mothers were obese (Table 3 ).

As regarding overweight/obese children $(n=64), 41(64.1 \%)$ and 34 (53.0\%) of them had their father and mother overweight/ obese respectively $(p<0.05, p<0.01)$.

Parents' educational level was high, since about $40 \%$ was graduated (Table 4). Among overweight/obese children, 51 $(80.3 \%)$ and $42(65.2 \%)$ of them had their father and mother with low educational level respectively $(p<0.01, p<0.05)$. About $50 \%$ of parents were in the medium socio-economic level, a few were unemployed $(3.9 \%)$ and about $20 \%$ of mothers were housewife (Table 4). Amongoverweight/obese children, 50 (78.7\%) and 54 $(84.0 \%)$ of them had their father and mother with medium-low family income respectively ( $p<0.01, p<0.05)$.

\section{Family Dietary Habits}

Family dietary habits are reported in Table 5 where frequency distributions of healthy foods choice are shown. Overall, healthy

\begin{tabular}{|c|c|c|}
\hline & $\mathrm{X} \pm \mathrm{DS}$ & Range \\
\hline $\mathrm{N}^{\circ}$ of family members & $4.14 \pm 1.2$ & $2-12$ \\
\hline $\mathrm{N}^{\circ}$ of children & $1.95 \pm 0.8$ & $1-7$ \\
\hline Fathers' age (years) & $43.0 \pm 6.1$ & $26-70$ \\
\hline Mothers' age (years) & $40.0 \pm 5.7$ & $22-61$ \\
\hline Fathers' BMI $\left(\mathrm{kg} / \mathrm{m}^{2}\right)$ & $25.3 \pm 3.2$ & $18.8-37.8$ \\
\hline Overweight fathers' BMI $\left(\mathrm{kg} / \mathrm{m}^{2}\right)$ & $\begin{array}{l}26.9 \pm 1.3 \\
(40.1 \%)^{*}\end{array}$ & $25.0-29.8$ \\
\hline Obese fathers' BMI $\left(\mathrm{kg} / \mathrm{m}^{2}\right)$ & $\begin{array}{c}32.5 \pm 2.0 \\
(7.8 \%)^{*}\end{array}$ & $30.2-37.7$ \\
\hline Mothers' BMI $\left(\mathrm{kg} / \mathrm{m}^{2}\right)$ & $22.3 \pm 3.7$ & $16.4-41.9$ \\
\hline Overweight mothers' BMI $\left(\mathrm{kg} / \mathrm{m}^{2}\right)$ & $\begin{array}{l}27.0 \pm 1.5 \\
(15.4 \%)^{*}\end{array}$ & $25.0-29.8$ \\
\hline Obese mothers' BMI $\left(\mathrm{kg} / \mathrm{m}^{2}\right)$ & $\begin{array}{c}32.7 \pm 3.3 \\
(4.2 \%)^{*}\end{array}$ & $30.0-42.0$ \\
\hline
\end{tabular}


Table 4: Parents' Educational and Socio-Economic Levels.

\begin{tabular}{|c|c|c|}
\hline Educational Level & Father (\%) & Mother (\%) \\
\hline Primary school & 3.8 & 2.7 \\
\hline Middle/Secondary school & 60.3 & 57.2 \\
\hline Graduated & 35.9 & 40.1 \\
\hline Family Income & Father (\%) & Mother (\%) \\
\hline Low level & 20.8 & 8.5 \\
\hline Medium level & 46.6 & 52.9 \\
\hline High level & 28.7 & 15.4 \\
\hline Unemployed & 3.9 & 3.9 \\
\hline Housewife & ----- & 19.3 \\
\hline
\end{tabular}

Table 5: Family Dietary Habits.

\begin{tabular}{|l|c|}
\hline Healthy Foods Choice & \% of Families \\
\hline Fresh fruit at least twice daily & 69.4 \\
\hline Fresh vegetables at least twice daily & 59.3 \\
\hline Wholegrain bread rather than white bread & 27.0 \\
\hline $\begin{array}{l}\text { Skimmed or semi-skimmed milk (low fat) rather than } \\
\text { whole milk }\end{array}$ & 59.5 \\
\hline Olive oil rather than seed oil & 96.8 \\
\hline Vegetable cooking fats rather than lard or butter & 87.0 \\
\hline Low-fat cheese rather than high-fat cheese & 70.5 \\
\hline
\end{tabular}

foods choice were usual for a large percentage of families, except for the consumption of whole grain bread rather than white bread which was less frequent (only $27.0 \%$ of families). According to the score used to classify unhealthy and healthy food habits, $17.3 \%$ of families gained a score $0-3$, while $82.7 \%$ obtained a score $\geq 4$, showing that most of the families had healthy dietary habits. The mean score was $4.7 \pm 1.3$.

\section{Association of Overweight plus Obesity with Dietary Habits, Physical Activity and Family Environment}

Mann-Whitney's test did not show any significant difference for BMI between children's genders. Bivariate analysis using chi square test was conducted to compare the differences between genders in the prevalence of normal weight and overweight plus obese subjects evaluated both as Cole's cut-off point reference standards for BMI [22]. Also in this case, the results did not show any significant difference between genders. Therefore, according to these results the analyses were conducted on the whole sample, not for gender separately.

Multiple logistic regression analysis was used to assess the effects of covariates (father and mother's BMI, parents' education and family income, children's physical activity, children's and family dietary habits) on dichotomous variable (children's BMI). Since father's and mother's BMI, education and income were strictly correlated among them $(p<0.01, p<0.01, p<0.05)$, only father's variables were used as covariates in the logistic model. The results are reported in Table 6 underlining a correlation between all the covariates and children's obesity, except for children's dietary habits, OR ranging from 1.163 (95\% CI 1.0671.269) for fathers' BMI to 2.101 (95\% Cl 1.124-3.926) for children's physical activity and $p<0.05$ for all the significantly correlated variables.

\section{Discussion}

This study, carried out as part of a wider nutritional surveillance project, was aimed at investigating the correlation between overweight and obesity and dietary habits, physical activity and family environment among primary school children in Pavia, Northern Italy and comparing our results with similar studies.

In the current study $92.5 \%$ of the recruited sample participated in the survey showing a high number of respondents with a similar distribution between gender. The age of 7-8 years is a period during which family environment may strongly influences children weight status and future lifestyle and dietary habits. Indeed, the role of parenting is particularly critical for young children because parents directly determine the child's physical and social environment and indirectly influence behaviors, habits and attitudes through socialization processes and modeling.

In the current study, the prevalence rate of overweight plus obese children was higher in males $(17.3 \%)$ than in females $(13.7 \%)$. The value in the total sample was equal to $15.9 \%$ and was lower than the most recent Italian national data collected in 2014 [7]. Our data are encouraging and are in line with those of a study carried out by Brambilla et al. [25], in 2012 in Milan Northern Italy, reporting a decrease in the prevalence rate of overweight/obesity in 2,117 children aged 5-6 years from $23.1 \%$ in 2001 to $16.6 \%$ in 2011 . In addition, they are in line with international epidemiological data [26] referring to nine European and non-European countries (Australia, China, England, France, Netherland, New Zealand, Sweden, Switzerland and USA) collected on 467,294 children aged 2-19 years, reporting that the increase in prevalence of overweight/obesity has slowed appreciably, or has even plateaued.

Therefore, it might be supposed that the childhood obesity epidemic is decreasing, but it should also be pointed out that our data and those collected in Milan and in Lombardy Region referred to selected age groups of children (7-8 years in Pavia, 5-6 years in Milan and 8-9 years in Lombardia) and to a specific area in Italy, then they need further in-depth research.

Children's dietary habits are satisfactory since only $1.4 \%$ had

Table 6: Logistic Regression Analysis of Family Environment, Children's Physical Activity and Dietary Habits Associated with Children's Overweight plus Obesity.

\begin{tabular}{|l|c|c|c|c|}
\hline Covariates & OR & P-value & OR 95.0\% CI \\
\hline & & & Lower & Upper \\
\hline Fathers' BMI & 1.163 & 0.001 & 1.067 & 1.269 \\
\hline Fathers' education level & 1.622 & 0.048 & 1.248 & 1.856 \\
\hline Family income & 1.399 & 0.045 & 1.128 & 1.546 \\
\hline Family dietary habits & 1.207 & 0.034 & 1.074 & 1.546 \\
\hline Children's physical activity & 2.101 & 0.020 & 1.124 & 3.926 \\
\hline Children's dietary habits & 1.183 & 0.097 & 1.089 & 1.367 \\
\hline
\end{tabular}


inadequate eating habits. Breakfast was consumed by almost the entire sample (91.8\%) including dairy products, fruit juice and cereals; daily snacks were qualitatively satisfactory; consumption of cakes and soft drinks was low (14.8\%); two portions/daily of fruit and vegetables were eaten by about half of the sample; the meals were correctly distributed along the day (90.8\%) and the diet was varied in about $80 \%$ of children.

Our results are in agreement with data obtained in other studies in Tuscany (Central Italy) among 8-9 years old children [27], in Spain among 6-10 years old children [28] and in Germany among 5-6 years old children [8]. On the other hand, they are better than those found in OKkio alla Salute survey (2014) [7].

Children from Pavia region generally are physical active since more than $40 \%$ of them were involved in dynamic outdoor games for one hour or more per day and $79.8 \%$ were used to practice sport along the year. Our findings are in agreement with other studies carried out in Sweden on 7-9 years old children [29] and in Mexico City on 6-12 years old children [30] and show better results than those obtained in OKkio alla Salute project in 2014 [7].

Family frame of our sample including parents with two children is typical of the actual Italian family [31], showing in our case young parents with medium-high cultural and socioeconomic levels. Prevalence rate of overweight fathers is higher than the Italian National data [32], but overweight fathers' BMI mean value $\left(26.9 \pm 1.3 \mathrm{~kg} / \mathrm{m}^{2}\right)$ is slightly above the adult cut off point for overweight reference standards for BMI $\left(25.0 \mathrm{~kg} / \mathrm{m}^{2}\right)$ according to WHO 2000 [3].

Family dietary habits showed healthy food habits since more than $80 \%$ of the sample ate fresh fruit and vegetables at least twice daily, chose wholegrain bread, semi skimmed or skimmed milk, low fat cheese and extra virgin olive oil both for dressing and cooking satisfying the healthy diet recommendations.

Since fathers and mother's BMI, education and income were strictly correlated among them, we used only father's variables as covariates in the logistic model. Multiple logistic regression analysis showed the influence of family environment on children's overweight/obesity underlining a statistical significant influence of parents' BMI, educational level, family income as well as dietary habits.

Parental BMI was associated with children's BMI, in agreement with previous studies [33-38] and seems to be a significant predictor of childhood obesity. On the other hand, having normal weight parents appears to have a protective effect against the risk of obesity. Indeed, in our sample, among children with both normal weight parents $\left(\mathrm{n}^{\circ}=179\right), 92.2 \%$ of them were normal weight while only $7.8 \%$ were overweight/obese.

Nevertheless, in this context the influence of the father seems to be stronger than that of the mother, since a larger number of overweight/obese children $\left(n^{\circ}=41,64.1 \%\right)$ had their father with a high BMI and a low educational level.

The parents' overweight is undoubtedly one of the most important factors influencing their children's weight status, but not the only one. Indeed the parents' educational level, socioeconomic status and family dietary habits directly determine the child's physical and social environment being responsible for the education, behaviour and lifestyle of their children.

In our study the families showed amedium-high educational level and a satisfactory socio-economic status as well as a good availability of healthy foods within the home, which could explain why the prevalence rate of overweight plus obese children in our sample was enough restrained (15.9\%). Among the variables regarding family environment, parental education was the one most strongly related, in an inverse manner, with children's obesity (OR=1.622). Our findings are in line with the results from other studies conducted in European and non- European countries [11-13, 29,39-45] underlining the influence of family environment on children's weight status.

Previous studies [46-50] suggest that encouraging children adopting an active lifestyle can prevent them from overweight and obesity. In this context parents play an important role in developing children's physical activity while creating a healthy home environment that stimulates physical activity and decreases sedentary lifestyle. In our study family environment influence was pointed out by the fact that $79.1 \%$ of children used to practice sport along the entire year had their father with a secondary school diploma or university degree as well as $84.1 \%$ of those practicing sport had their father with medium-high income. We might argue that a high level family environment promotes a healthy and active lifestyle protective against the risk of obesity.

Children's physical activity was significantly associated to their weight status (OR 2.101, $p=0.020$ ) while their dietary habits were not (OR 1.183, $p=0.097$ ). This latter is in disagreement with the data in literature, possibly because of methodological limitations. Indeed, the questionnaire regarding children's dietary habits was drawn from a previous one [18] developed and validated for adolescents and filled in by the parents themselves and therefore should be validated on children aged 7-9 years.

Particular strengths of this study were the large number of participating subjects representing the entire population of children aged 7-8 years living in Pavia, the very high participating rate $(92.5 \%)$, the children's anthropometric measurements assessed by standardized method, the high response rate of the families to the questionnaire and finally the information collected by the questionnaire giving a full comprehension of the family environment.

There are also a few limitations that have to be acknowledged. Parents' anthropometric measurements were self-reported since we could not measure them directly, even though the validity of self-reported height and weight by young adults was suggested to be reliable for identifying relationships in several epidemiological studies $[45,51,52]$. Other limitations are that the questionnaire section regarding children's dietary habits was not validated for this age and the age range of the study population did not cover all age childhood period. Finally, because of the cross sectional nature of our study, it provides only evidence that will be 
investigated by the follow-up study actually in progressing.

Our study underlines that children's weight status derives from a number of determinants influencing the acquisition of behaviours which either might be at risk of beneficial for their health. As widely described in the literature, beyond the genetic predisposition, our data agree with the influence of family environment on children's weight status and therefore on the increasing risk of obesity. Given that the family factors on children's weight status are often related to each other, it is difficult to establish the true effect of each one that needs to be investigated by specific longitudinal studies.

In conclusion, these findings strengthen the need for implementing public health interventions and educational strategies in primary schools aimed at involving the parents to achieve children's consistent behavioural changes, because of the relevance of family environment on the prevention of childhood overweight. In addition, target interventions are needed on children with obese parents and low social economic status providing social support.

\section{Declarations}

The Authors state that there are no financial or other contractual agreements that might cause conflicts of interest nor any personal financial interest in the work neither any commercial sponsor. The study was conducted according to the guidelines laid down in the Declaration of Helsinki and all procedures involving human subjects were approved by the Ethics Committees of Pavia University Medical School. Informed written consent was obtained from children's parents by means of a signed letter.

\section{References}

1. Turconi G, Rossi M , Testa L , Moro S , Roggi C and Maccarini L. Overweight, Obesity and Abdominal Obesity in Primary School Children in Pavia, Northern Italy. J Nutr and Health. 2014; 1: 101.

2. Han JC, Lawlor DA, Kimm SY. Childhood obesity. Lancet. 2010 15; 375(9727): 1737-48. doi: 10.1016/S0140-6736(10)60171-7.

3. World Health Organization (WHO). Obesity: preventing and managing the global epidemic Report of a WHO Consultation (WHO Technical Report Series 894. World Health Organization, Geneva, Switzerland, 2000 .

4. Lobstein T, Baur L, Uauy R; IASO International Obesity Task Force. Obesity in children and young people: a crisis in public health. Obes Rev. 2004; 5 Suppl 1: 4-104.

5. Gupta N, Goel K, Shah P, Misra A. Childhood obesity in developing countries: epidemiology, determinants, and prevention. Endocr Rev. 2012; 33(1): 48-70. doi: 10.1210/er.2010-0028.

6. Lobstein T, Baur LA. International Obesity Taskforce (IOTF). The Global Epidemic. 2012.

7. Ministero della Salute. Sistema di Sorveglianza OKkio alla Salute: sintesi dei risultati del 2014.

8. Toschke AM, Thorsteinsdottir KH, von Kries R; GME Study Group. Meal frequency, breakfast consumption and childhood obesity. Int J Pediatr Obes. 2009; 4(4): 242-8. doi: 10.3109/17477160902763341.
9. Sandercock GR, Voss C, Dye L. Associations between habitual schoolday breakfast consumption, body mass index, physical activity and cardiorespiratory fitness in English schoolchildren. Eur J Clin Nutr. 2010; 64(10): 1086-92. doi: 10.1038/ejcn.2010.145.

10. Eloranta AM, Lindi V, Schwab U, Tompuri T, Kiiskinen S, Lakka HM, et al. Dietary factors associated with overweight and body adiposity in Finnish children aged 6-8 years: the PANIC Study. Int J Obes (Lond). 2012; 36(7): 950-5. doi: 10.1038/ijo.2012.89

11. Mushtaq MU, Gull S, Mushtaq K, Shahid U, Shad MA, Akram J. Dietary behaviors, physical activity and sedentary lifestyle associated with overweight and obesity, and their socio-demographic correlates, among Pakistani primary school children. Int J Behav Nutr Phys Act. 2011 25; 8: 130. doi: 10.1186/1479-5868-8-130.

12. van Stralen MM, te Velde SJ, van Nassau F, Brug J, Grammatikaki E, Maes L, et al. Weight status of European preschool children and associations with family demographics and energy balance-related behaviours: a pooled analysis of six European studies. Obes Rev. 2012; 13 Suppl 1:29-41. doi: 10.1111/j.1467-789X.2011.00959.x.

13. Thibault H, Carriere C, Langevin C, Kossi Déti E, Barberger-Gateau $\mathrm{P}$, Maurice S. Prevalence and factors associated with overweight and obesity in French primary-school children. Public Health Nutr. 2013; 16(2): 193-201. doi: 10.1017/S136898001200359X.

14.Danielzik S, Czerwinski-Mast M, Langnäse K, Dilba B, Müller MJ. Parental overweight, socioeconomic status and high birth weight are the major determinants of overweight and obesity in 5-7 y-old children: baseline data of the Kiel Obesity Prevention Study (KOPS). Int J Obes Relat Metab Disord. 2004; 28(11): 1494-502.

15. Must A, Tybor DJ. Physical activity and sedentary behavior: a review of longitudinal studies of weight and adiposity in youth. Int J Obes (Lond). 2005; 29 Suppl 2: S84-96.

16. Kleiser C, Schaffrath Rosario A, Mensink GB, Prinz-Langenohl R, Kurth BM. Potential determinants of obesity among children and adolescents in Germany: results from the cross-sectional KiGGS Study. BMC Public Health. 2009 2; 9: 46. doi: 10.1186/1471-2458-9-46.

17. G. Lohman, Alex F. Roche, Reynaldo Martorell, (1988) Anthropometric standardization reference manual. Champaign, IL: Human kinetics Books, 1988.

18. Turconi G, Celsa M, Rezzani C, Biino G, Sartirana MA, Roggi C. Reliability of a dietary questionnaire on food habits, eating behaviour and nutritional knowledge of adolescents. Eur J Clin Nutr. 2003; 57(6): 753-63.

19. Turconi G, Guarcello M, Maccarini L, Cignoli F, Setti S, Bazzano R, et al. Eating Habits and Behaviors, Physical Activity, Nutritional and Food Safety Knowledge and Beliefs in an Adolescent Italian Population. J Am Coll Nutr. 2008; 27(1): 31-43.

20. World Health Organization (WHO). Food-based Dietary Guidelines in the WHO European Region. Copenhagen: WHO Regional Office for Europe, 2003.

21. International Obesity Task Force (IOTF). Establishing a standard definition for child overweight and obesity worldwide: international survey in Childhood Obesity. 2003.

22. Cole TJ, Lobstein T. Extended international (IOTF) body mass index cut-offs for thinness, overweight and obesity. Pediatr Obes. 2012; 7(4): 284-94. doi: 10.1111/j.2047-6310.2012.00064.x.

23. Lallukka T, Laaksonen M, Rahkonen O, Roos E, Lahelma E, et al. Multiple socio-economic circumstances and healthy food habits. Eur J Clin Nutr. 2007; 61(6): 701-10. 
24. Roos E, Sarlio-Lähteenkorva S, Lallukka T, Lahelma E. Associations of work-family conflicts with food habits and physical activity. Public Health Nutr. 2007; 10(3): 222-9.

25. Brambilla P, Vezzoni M, Lucchini R, Acerbi L, Brambilla A, Brandolini $\mathrm{G}$, et al. Is the prevalence of overweight reducing at age 5-6 years? Ten years data collection in ASL Milano 2. Ital J Pediatr. 2012 8; 38:24. doi: 10.1186/1824-7288-38-24.

26. Olds T, Maher C, Zumin S, Péneau S, Lioret S, Castetbon K, et al. Evidence that the prevalence of childhood overweight is plateauing: data from nine countries. Int J Pediatr Obes. 2011; 6(5-6): 342-60. doi: 10.3109/17477166.2011.605895.

27. Lazzeri G, Giallombardo D, Guidoni C, Zani A, Casorelli A, Grasso A, et al. Nutritional surveillance in Tuscany: eating habits at breakfast, midmorning and afternoon snacks among 8-9 y-old children. J Prev Med Hyg. 2006; 47(3): 91-9.

28. Rodríguez Huertas E, Solana Moreno MI, Rodríguez Espinosa F, Rodríguez Moreno MJ, Aguirre Rodríguez JC, Alonso Ródenas M. CASERIA program (Healthy Habits in Primary School Questionnaire). Responses of 6 to 10 year-old children. Semergen. 2012; 38(5): 26577. doi: 10.1016/j.semerg.2011.10.018.

29. Moraeus L, Lissner L, Olsson L, Sjöberg A. Age and time effects on children's lifestyle and overweight in Sweden. BMC Public Health. 2015 10; 15: 355. doi: 10.1186/s12889-015-1635-3.

30. Vilchis-Gil J, Galván-Portillo M, Klünder-Klünder M, Cruz M, FloresHuerta S. Food habits, physical activities and sedentary lifestyles of eutrophic and obese school children: a case-control study. BMC Public Health. 2015 11; 15: 124. doi: 10.1186/s12889-015-1491-1.

31. ISTAT. Istituto Nazionale di Statistica. Popolazione e Famiglie, 2014.

32. Epicentro. Il portale dell'epidemiologia per la Sanità Pubblica. La Sorveglianza Passi, 2011-2014.

33. Monasta L, Batty GD, Cattaneo A, Lutje V, Ronfani L, Van Lenthe FJ, et al. Early-life determinants of overweight and obesity: a review of systematic reviews. Obes Rev. 2010; 11(10): 695-708. doi: 10.1111/j.1467-789X.2010.00735.x.

34. Berkowitz RI, Stallings VA, Maislin G, Stunkard AJ. Growth of children at high risk of obesity during the first $6 \mathrm{y}$ of life: implications for prevention. Am J Clin Nutr. 2005; 81(1): 140-6.

35. He Q, Ding ZY, Fong DY, Karlberg J. Risk factors of obesity in preschool children in China: a population-based case-control study. Int J Obes Relat Metab Disord. 2000; 24(11): 1528-36.

36. Jouret B, Ahluwalia N, Cristini C, Dupuy M, Nègre-Pages L, Grandjean $\mathrm{H}$, et al. Factors associated with overweight in preschool-age children in southwestern France. Am J Clin Nutr. 2007; 85(6): 1643-9.

37. Keane E, Layte R, Harrington J, Kearney PM, Perry IJ. Measured Parental Weight Status and Familial Socio- Economic Status Correlates with Childhood Overweight and Obesity at Age 9. PLoS One. 2012; 7(8): e43503. doi: 10.1371/journal. pone. 0043503.

38. Semmler C, Ashcroft J, van Jaarsveld CH, Carnell S, Wardle J. Development of overweight in children in relation to parental weight and socioeconomic status. Obesity (Silver Spring). 2009; 17(4): 81420. doi: 10.1038/oby.2008.621.

39. Lazzeri G, Pammolli A, Pilato V, Giacchi MV. Relationship between 8/9-yr-old school children BMI, parents' BMI and educational level: a cross sectional survey. Nutr J. 2011 19; 10: 76. doi: 10.1186/14752891-10-76.

40. Lazzeri G, Casorelli A, Giallombardo D, Grasso A, Guidoni C, Menoni E, et al. Nutritional Surveillance in Tuscany. Relationship between 8-9 y-old school children BMI and parents' BMI and educational level. J Prev Med Hyg. 2006 ; 47(1): 16-21.

41. Lamerz A, Kuepper-Nybelen J, Wehle C, Bruning N, Trost-Brinkhues $\mathrm{G}$, Brenner $\mathrm{H}$, et al. Social class, parental education, and obesity prevalence in a study of six-year-old children in Germany. Int J Obes (Lond). 2005; 29(4): 373-80.

42. Knai C, Lobstein T, Darmon N, Rutter H, McKee M. Socioeconomic Patterning of Childhood Overweight Status in Europe. Int J Environ Res Public Health. 2012; 9(4): 1472-89. doi: 10.3390/ijerph9041472.

43. Farajian P, Panagiotakos DB, Risvas G, Karasouli K, Bountziouka $\mathrm{V}$, Voutzourakis $\mathrm{N}$, et al. Socio-economic and demographic determinants of childhood obesity prevalence in Greece: the GRECO (Greek Childhood Obesity) study. Public Health Nutr. 2013; 16(2): 240-7. doi: 10.1017/S1368980012002625.

44.Wang Z, Patterson CM, Hills AP. Association between overweight or obesity and household income and parental body mass index in Australian youth: analysis of the Australian National Nutrition Survey, 1995. Asia Pac J Clin Nutr. 2002; 11(3): 200-5.

45. Valerio G, D'Amico O, Adinolfi M, Munciguerra A, D’Amico R, Franzese A. Determinants of weight gain in children from 7 to 10 years. Nutr Metab Cardiovasc Dis. 2006; 16(4): 272-8

46. Epstein LH, Roemmich JN, Robinson JL, Paluch RA, Winiewicz $\mathrm{DD}$, Fuerch JH, et al. A randomized trial of the effects of reducing television viewing and computer use on body mass index in young children. Arch Pediatr Adolesc Med. 2008 ; 162(3):239-45. doi: 10.1001/archpediatrics.2007.45.

47. Fitzgibbon ML, Stolley MR, Schiffer L, Van Horn L, KauferChristoffel K, Dyer A. Two-year follow-up results for Hip-Hop to Health Jr.: a randomized controlled trial for overweight prevention in preschool minority children. J Pediatr. 2005 ; 146(5): 618-25.

48. Kain J, Uauy R, Albala, Vio F, Cerda R, Leyton B. School-based obesity prevention in Chilean primary school children: methodology and evaluation of a controlled study. Int J Obes. Relat. Metab. Disord. 2004; 28(4): 483-493.

49. Sallis JF, McKenzie TL, Conway TL, Elder JP, Prochaska JJ, Brown M, et al. Environmental interventions for eating and physical activity: a randomized controlled trial in middle schools. Am J Prev Med. 2003; 24(3): 209-17.

50. Kyung Rhee. Childhood overweight and the relationship between parent behaviors, parenting style, and family functioning. The Annals of the American Academy of Political and Social Science. 2008; 615(1): 11-37. doi: 10.1177/0002716207308400.

51. Spencer EA, Appleby PN, Davey GK, Key TJ. Validity of self-reported height and weight in 4808 EPIC-Oxford participants. Public Health Nutr. 2002; 5(4): 561-5.

52. Kuczmarski MF, Kuczmarski RJ, Najjar M. Effects of age on validity of self-reported height, weight, and body mass index: findings from the Third National Health and Nutrition Examination Survey, 1988-1994. J Am Diet Assoc. 2001; 101(1): 28-34; quiz 35-6. 